\title{
Profile Characterization and Temperature Effect on the Wettability of Microstructured Surfaces
}

\author{
Yuxuan Han' ${ }^{*}$, Yingwei Liu'2, Minami Kaneko', Fumio Uchikoba1 \\ ${ }^{1}$ Department of Precision Machinery Engineering, College of Science and Technology, Nihon University, Funabashi, Japan \\ ${ }^{2}$ Department of Mechanical Design, Xi'an University of Technology, Xi'an, China \\ Email: *cc_hanyuxuan@hotmail.com
}

How to cite this paper: Han, Y.X., Liu, Y.W., Kaneko, M. and Uchikoba, F. (2018) Profile Characterization and Temperature Effect on the Wettability of Microstructured Surfaces. Journal of Surface Engineered Materials and Advanced Technology, 8, 83-94.

https://doi.org/10.4236/jsemat.2018.84008

Received: July 10, 2018

Accepted: September 4, 2018

Published: September 7, 2018

Copyright $\odot 2018$ by authors and Scientific Research Publishing Inc. This work is licensed under the Creative Commons Attribution International License (CC BY 4.0).

http://creativecommons.org/licenses/by/4.0/

\begin{abstract}
Wetting is one of the omnipresent phenomena governed via natural laws. Moreover, surface wettability at non-ambient temperature especially at high temperature $\left(30^{\circ} \mathrm{C}\right.$ to $\left.90^{\circ} \mathrm{C}\right)$ is of great importance in many industrial processes. In this study, $\mathrm{Si}$ wafers with various structures were fabricated to investigate wettability at different temperatures. Three shapes with micro-pillar structured surfaces were designed and fabricated. Pillar-structured surfaces were fabricated by photolithography and ICP etching. The temperature-dependent wettability of single-phase regime droplets was characterized using contact angle measurements. The wetting behavior of a water droplet was observed.
\end{abstract}

\section{Keywords}

Wetting, Microstructured Surface, Temperature Effect, Contact Angle

\section{Introduction}

Wetting is a normal phenomenon that exists widely in the natural world. Many lives take a wetting advantage to adapt to their living environment [1] [2] such as the lotus leaves and the fish scale, which have a self-cleaning property [3] [4]. Water striders can walk on the water surface [5], butterfly wings show the directional adhesion [3] [6], mosquito eyes are antifogging [7], and the Namib Desert beetle and spider silk collect the water [8] [9]. Controlling the behavior of wetting on solid surfaces has wide applications such as the heat transfer, microfluidic system (e.g. fluid flow manipulation in lab on chip devices), and designing better surfaces to inhibit corrosion and antifouling. Researchers have been trying 
to discuss the wetting phenomenon for a long time but the complexity of this multi-scale phenomenon still has left much to be understood.

Since Wenzel reported the effect of roughness on surface wettability [10], researchers found the way to enhance the wetting by modifying the surface roughness. Recent advances in micromachining and nanofabrication technology have granted researchers the ability to control surface texture and properties. This, combined with the fact that surface forces become increasingly important on a small scale, makes it an opportune time to focus studies in the area [11]. Both hydrophilic [12] and hydrophobic [13] [14] micro-structured surfaces have attracted much attention.

Droplets on micro-structured surfaces can generally adopt two different states [15]. The Wenzel state in which the liquid completely wets the entire surface (see Figure 1(a)), or the Cassie-Baxter state in which the droplet only partly wets the surface, which leaves air in between the microstructures under the droplet (see Figure 1(b)). Wenzel proposed that the apparent droplet contact angle in case of complete wetting of the micro-structured surface is influenced by the increase of the wetted area (compared to a droplet on a similar flat surface). Understanding liquid-solid contact [2] and developing applications are core issue of the wetting research.

Moreover, surface wettability at a high temperature $\left(30^{\circ} \mathrm{C}\right.$ to $\left.90^{\circ} \mathrm{C}\right)$ is important in industrial processes [16] such as water transportation and metal processing [17]. Recently, several advances have been made such as the following: superhydrophobic surface hot water repellent [18]; the nucleate boiling based on the lyophilic micro-structured surface leads high critical heat flux [19]; the fabrication of wetting-controllable thermally responsive materials [20] [21]; wetting transition on hydrophobic microstructures surface during evaporation [22] [23] [24]; low temperature heat exchange on hydrophobic surfaces [25]. The theory and applications of droplet wetting behavior on hot surfaces are very important in the solid-liquid heat transfer system [26].

However, the effect of surface morphology and temperature effect on the wetting behavior at high temperatures have not been studied systematically. The investigation of the wetting behavior of surfaces with different micro-structures from $30^{\circ} \mathrm{C}$ to $90^{\circ} \mathrm{C}$ was described in this paper. Three kinds of micro-structured

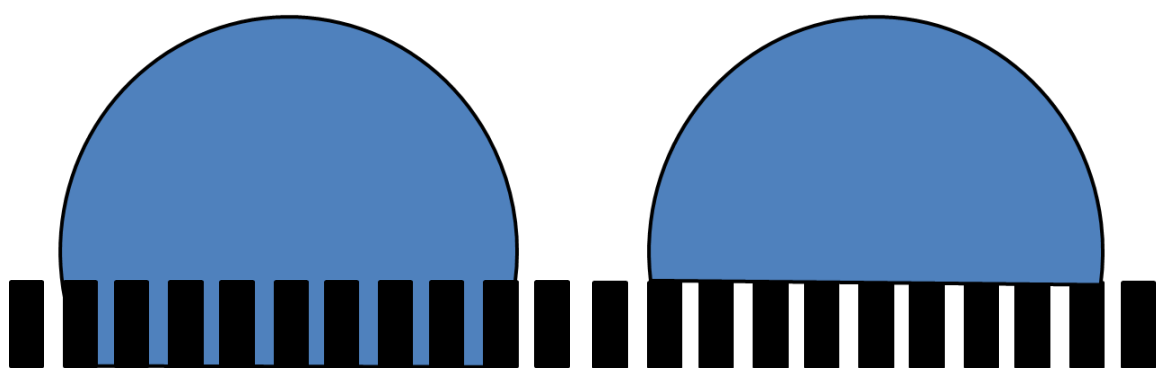

(a)

(b)

Figure 1. States of droplets on the micro-structured surface. (a) Wenzel state; (b) Cassie-Baxter state. 
surfaces with different wettability were successfully fabricated on the Si wafer by using photolithography and ICP etching technology. The wetting behavior of a water droplet was discussed and found to be different on the surfaces when the wetting transition occurred at a specific temperature.

\section{Theoretical Analysis}

The contact angle $\theta$ on a smooth surface (as shown in Figure 2) was given by the Young equation [27].

$$
\cos \theta=\left(\gamma_{-} S V-\gamma_{-} S L\right) / \gamma_{-} L V
$$

where $\gamma_{S V}, \gamma_{S L L}$ and $\gamma_{L V}$ are the surface tension coefficients on solid-vapor, solid-liquid, and liquid-vapor interfaces, respectively.

Both the Wenzel and Cassie-Baxter state has the following relation with the intrinsic contact angle $\theta$ and the topography of the roughness structure. The wetting characteristic of such a surface was first addressed by Cassie and Baxter [28] and the apparent contact angle $\theta c$ was predicted by the following equation.

$$
\cos \theta c=\left(\gamma_{-S V}^{*}-\gamma_{-}^{*} S L\right) / \gamma_{-} L V
$$

where $\gamma_{-S V}^{*}=f \gamma_{-} S V$ and $\gamma_{-}^{*}{ }_{S L}=(1-f) \gamma_{-L V}+f \gamma_{-} S L, f$ is the area fraction. Researchers considered the three-phase contact line tension on the liquid-vapor-solid phase boundary and presented a new model to predict the contact angle of a water droplet on a rough surface [29] [30] [31] [32].

$$
\cos \theta^{*}=-1+(1+\cos \theta)\left(1-\lambda /\left(K(1+\cos \theta) \gamma_{-} L V\right)\right) f
$$

where $\lambda$ is the line tension and $K$ is the influence coefficient of scale effect.

\section{Experiments}

\subsection{Fabrication of Micro-Structured Surfaces}

Silicon wafers with various structures were fabricated to investigate wettability at different temperatures. Three shapes with micro-pillar structured surfaces were designed and fabricated in this paper. The side lengths of the square and triangle pillars were $10 \mu \mathrm{m}$ and the Hexagon pillars' side length was $5 \mu \mathrm{m}$, which is shown in Figure 3. The parameters of these three geometric patterns are shown in Table 1.

Pillar-structured surfaces were fabricated by photolithography and inductively coupled plasma (ICP) etching. These micropillars were uniformly distributed in a rectangular grid on a glass mask with different values of the area fraction $\mathrm{f}$. A

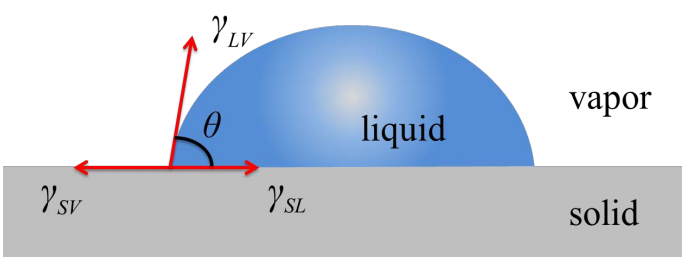

Figure 2. Illustration of the contact angle. 


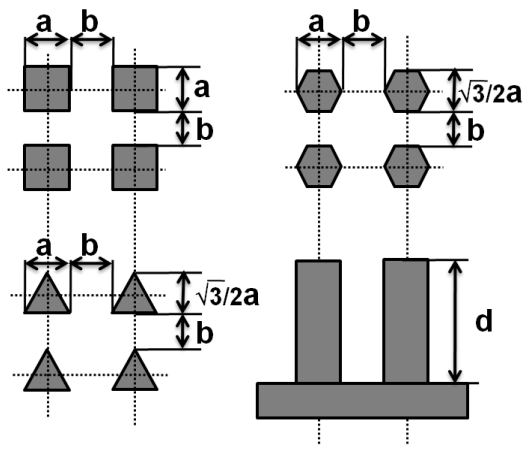

Figure 3. Microstructure distribution diagram.

Table 1. Characterization of microstructure geometric parameters.

\begin{tabular}{ccc}
\hline Shape of micro pillar & Area fraction $f$ & $K$ \\
\hline Square & $\frac{a^{2}}{(a+b)^{2}}$ & $\frac{a}{4}$ \\
Triangle & $\frac{\sqrt{3} a^{2}}{(\sqrt{3} a+2 b)^{2}}$ & $\frac{\sqrt{3}}{12} a$ \\
Hexagon & $\frac{3 \sqrt{3} a^{2}}{2(\sqrt{3} a+b)(2 a+b)}$ & $\frac{\sqrt{3}}{4} a$ \\
\hline
\end{tabular}

Silicon wafer ((100), 4 Inch, $400 \mu \mathrm{m}$ thick, p-type) was first clear and dry in the clean room and then the positive photoresist (S1805) was coated on the Si surface by a spin-coater. In the next step, the required pattern was transferred from the mask to the photoresist layer by UV exposure and the photoresist was partly removed in the developer. The uncovered Si was etched in the ICP etcher to finally fabricate the roughness pattern on the $\mathrm{Si}$ wafer. The residual photoresist was cleared away by the acetone. Etching experiments were performed in an STS Inductively Coupled Plasma system [33].

The fixed pillar heights $(d=10 \mu \mathrm{m}$ and $20 \mu \mathrm{m})$ for all the pillar-structured surfaces was achieved by controlling the etching circles. The fabricated micro-structured surfaces were measured by the Confocal Laser Scanning Microscope (CLSM), LEXTOLS4000, OLYMPUS. The fabricated micro-pillars' parameters and profiles were shown in Table 2, Table 3, and Figure 4. The fabricated microstructures have a small amount of manufacturing error in the mask error and fabrication process, but the error was within a reasonable error range.

The roughness on the micro-pillar top was an important parameter due to the droplet contact with the micro-pillar surface on these areas. On the basis of the topography observed by the Confocal Laser Scanning Microscope (CLSM) and Atomic Force Microscope (AFM), the top surface on the micro-pillar was relatively smooth and had a root mean square roughness of $0.433 \mathrm{~nm}(5 \mu \mathrm{m} \times 5 \mu \mathrm{m})$ (as shown in the Figure 5). Therefore, the effect of the roughness on the top of the micro-pillar could be neglected in the contact angle test. The surface roughness $\mathrm{Ra}$ of the bottom etched Si surface was approximately $0.2 \mu \mathrm{m}$. 


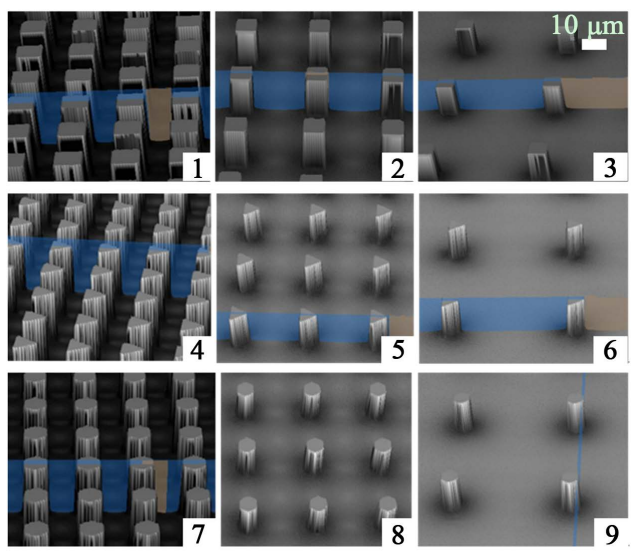

Figure 4. Three-dimensional images of micro-pillars with designed $h=20 \mu \mathrm{m}$, (1), (2), and (3) shown the $a=10 \mu \mathrm{m}$ square micro-pillar structures with different space between the pillars, $b=10 \mu \mathrm{m}, 25 \mu \mathrm{m}$, and $50 \mu \mathrm{m}$ respectively. (4), (5), and (6) shows the $\mathrm{a}=10 \mu \mathrm{m}$ triangle micro-pillar structures with different spaces between the pillars. $b=10 \mu \mathrm{m}, 25 \mu \mathrm{m}$, and $50 \mu \mathrm{m}$ respectively. (7), (8), and (9) shown the $a=10 \mu \mathrm{m}$ hexagon micro-pillar structures (Side length $=5 \mu \mathrm{m}$ ) with different space between the pillars $b=10 \mu \mathrm{m}, 25 \mu \mathrm{m}$, and $50 \mu \mathrm{m}$, respectively.

Table 2. Actual measured parameters of microstructure with $d=10 \mu \mathrm{m}$.

\begin{tabular}{cccccc}
\hline Sample & $\begin{array}{c}\text { Geometric } \\
\text { designs }\end{array}$ & $\begin{array}{c}\text { Side } \\
\text { length a }(\mu \mathrm{m}) \\
(10,10,5 \mu \mathrm{m})\end{array}$ & $\begin{array}{c}\text { Space } b(\mu \mathrm{m}) \\
(10,25,50 \mu \mathrm{m})\end{array}$ & $\begin{array}{c}\text { Depth } d(\mu \mathrm{m}) \\
(10 \mu \mathrm{m})\end{array}$ & $\begin{array}{c}\text { Area } \\
\text { fraction } f\end{array}$ \\
\hline SQU a10-b10-d10 & Square 1 & 10.120 & 9.986 & 10.882 & 0.2533 \\
SQU a10-b25-d10 & Square 2 & 9.933 & 24.540 & 12.415 & 0.0838 \\
SQU a10-b50-d10 & Square 3 & 9.867 & 49.333 & 14.694 & 0.0278 \\
TRI a10-b10-d10 & Triangle 4 & 10.373 & 10.373 & 12.656 & 0.1244 \\
TRI a10-b25-d10 & Triangle 5 & 9.867 & 25.299 & 11.147 & 0.0268 \\
TRI a10-b50-d10 & Triangle 6 & 9.614 & 50.345 & 11.868 & 0.0116 \\
HEX a10-b10-d10 & Hexagon 7 & 5.819 & 9.590 & 15.251 & 0.2107 \\
HEX a10-b25-d10 & Hexagon 8 & 5.819 & 25.046 & 12.715 & 0.0683 \\
HEX a10-b50-d10 & Hexagon 9 & 6.072 & 49.586 & 13.244 & 0.0258 \\
\hline
\end{tabular}

Table 3. Actual measured parameters of microstructure with $d=20 \mu \mathrm{m}$.

\begin{tabular}{cccccc}
\hline Sample & $\begin{array}{c}\text { Geometric } \\
\text { Designs }\end{array}$ & $\begin{array}{c}\text { Side } \\
\text { Length }(\mu \mathrm{m}) \\
(10,10,5 \mu \mathrm{m})\end{array}$ & $\begin{array}{c}\text { Space }(\mu \mathrm{m}) \\
(10,25,50 \mu \mathrm{m})\end{array}$ & $\begin{array}{c}\text { Depth }(\mu \mathrm{m}) \\
(20 \mu \mathrm{m})\end{array}$ & $\begin{array}{c}\text { Area } \\
\text { fraction f }\end{array}$ \\
\hline SQU a10-b10-d20 & Square 1 & 10.879 & 9.361 & 20.226 & 0.2889 \\
SQU a10-b25-d20 & Square 2 & 10.879 & 24.540 & 19.325 & 0.0943 \\
SQU a10-b50-d20 & Square 3 & 10.626 & 49.333 & 20.288 & 0.0314 \\
TRI a10-b10-d20 & Triangle 4 & 9.843 & 9.867 & 19.138 & 0.1240 \\
TRI a10-b25-d20 & Triangle 5 & 10.095 & 25.238 & 18.165 & 0.0398 \\
TRI a10-b50-d20 & Triangle 6 & 9.590 & 50.233 & 18.799 & 0.0117 \\
HEX a10-b10-d20 & Hexagon 7 & 6.057 & 9.108 & 20.890 & 0.2376 \\
HEX a10-b25-d20 & Hexagon 8 & 7.067 & 24.287 & 19.294 & 0.0925 \\
HEX a10-b50-d20 & Hexagon 9 & 6.309 & 49.839 & 19.530 & 0.0255 \\
\hline
\end{tabular}




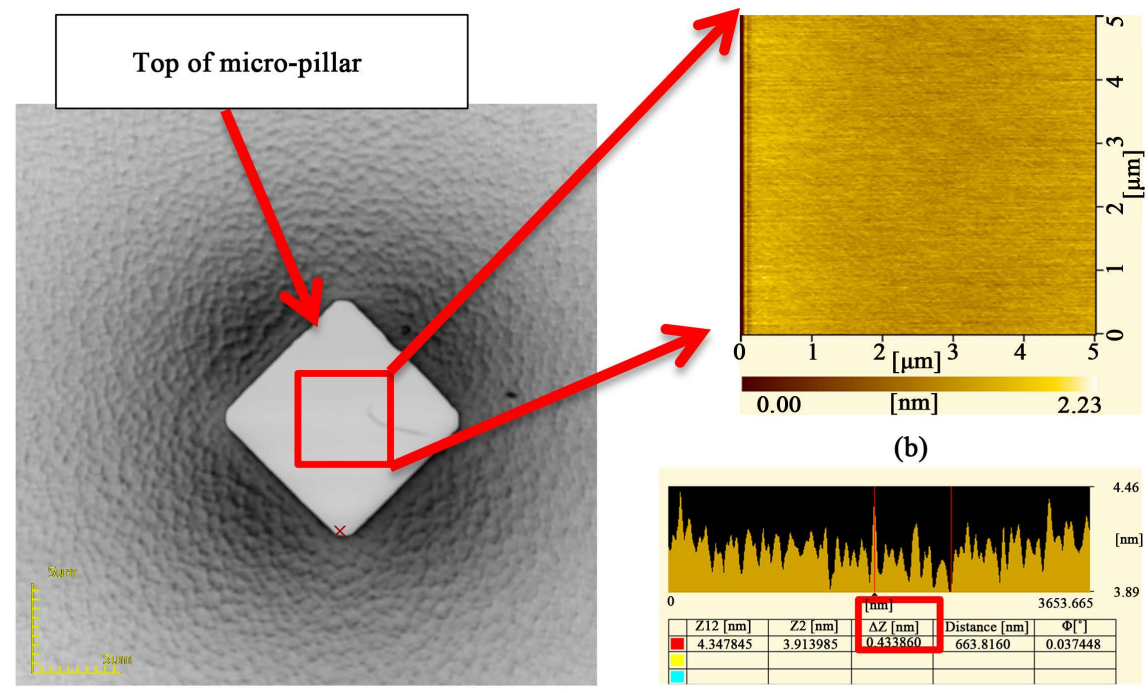

(a)

(c)

Figure 5. Morphology of the micro-pillar top surface. (a) CLSM image of the square micro-pillar; (b), (c) AFM images of the typical topography of the micro-pillar top surface $(5 \mu \mathrm{m} \times 5 \mu \mathrm{m})$. The root mean square roughness is $0.433 \mathrm{~nm}$.

\subsection{Contact Angle Measurement}

Gas-liquid-solid interfaces of droplets on a micro-structured surface can be continuous in the single-phase regime. The temperature-dependent wettability of single-phase regime droplets was characterized using contact angle measurements. Contact angle (CA) measurements were assessed at different temperatures with the KRUSS temperature controlled chamber TC21 for the temperature control of samples and Droplet Sharp Analyzer DSA25 for a contact angle measurement, which places a water droplet of $10 \mu \mathrm{L}$ (volume for a drop to not be affected by gravity) on the micro-structured substrate.

In a real system, however, a range of contact angles is usually obtained instead. The upper limit of the range is the advancing contact angle $\theta_{A}$, which is the contact angle found at the advancing edge of a liquid drop. The lower limit is the receding contact angle $\theta_{R}$, which is the contact angle found at the receding edge. In this study, both the advancing and receding angles were measured by slowly pumping liquidin to or out of a droplet. The static advancing and receding contact angles were measured three times using the polynomial fitting method on each surface.

The used DI water $(18.2 \mathrm{M} \Omega \cdot \mathrm{cm})$ was purified in a DI water system. The fabricated Si wafer was cleared by the RCA cleaning process before taking the contact angle measurement.

\section{Results and Discussion}

On micro-structured surfaces, droplets can have many CAs and a droplet on a surface must have a stable point at the energetically lowest point. The CA at this point was called the equilibrium CA. The equilibrium CA was calculated using 
the Tadmor equation [34] from our data of the advancing and receding contact angles. The hysteresis was determined by some dimensionless parameter which was normalized line energy. All the droplets were Cassie-Baxter state on the microstructured surfaces but the droplet on the square-pillar surface with pillar space $b=50 \mu \mathrm{m}$ and pillar height $d=10 \mathrm{um}$ at $50^{\circ} \mathrm{C}$.

$$
\theta=\arccos \left(\frac{\tau_{A} \cos \theta_{A}+\tau_{R} \cos \theta_{R}}{\tau_{A}+\tau_{R}}\right)
$$

where $\tau_{A} \equiv\left(\frac{\sin ^{3} \theta_{A}}{\left(2-3 \cos \theta_{A}+\cos ^{3} \theta_{A}\right)}\right)^{1 / 3}$ and $\tau_{R} \equiv\left(\frac{\sin ^{3} \theta_{R}}{\left(2-3 \cos \theta_{R}+\cos ^{3} \theta_{R}\right)}\right)^{1 / 3}$.

\subsection{Profile Characterization and Temperature Effect on Contact Angle}

Figure 6 indicates the effect of profile characterization of the micro-structured surfaces effect on CAs. Since the roughness enhances the wetting, the micro-structured surfaces have the larger contact angle than the smooth surface. The CAs were decreased and the area fraction $f$ decreases when the space between the pillars become wider. When the pillar height increases, the equilibrium CA increases. The contact angles on the micro-structured surface with different temperatures $\left(30^{\circ} \mathrm{C}\right.$ to $\left.90^{\circ} \mathrm{C}\right)$ were shown in Figure 6. The CAs decreased with temperature increases with pillar height was $20 \mathrm{um}$. As shown in Figure 6(a) and Figure 6(b), for surfaces with hexagon micro-pillars, the CAs on these surfaces with the higher micro-pillars were more lineally with temperature increasing, the air layer in the micro-pillars buffered the temperature effect. The similar results also were shown on the surface with square and triangle micro-pillars.

Pillar height was $10 \mu \mathrm{m}$ and the CA curve of the micro-pillar surface with space $\mathrm{b}$ was $10 \mu \mathrm{m}$, which rose first and then went down when the sample was heated. The CA curves of the hexagon- and triangle-pillar surfaces with space $b$ were $20 \mu \mathrm{m}$ also rose first and then went down when the sample was heated. But CA curves of the surface with square-pillars had shown the different way, which went down first and then rose when the sample was heated. When the space $b$ was $50 \mu \mathrm{m}$, the CA curve of these micro-pillar surfaces shown the lineal change with temperature increase. This phenomenon caused by heated air layer in the micro-pillars and the temperature affected surface tension coefficients.

\subsection{Shape and Temperature Effect on Contact Angle}

Figure 7 indicates the effect of the shape of the micro-structured surfaces on CA. The Hexagon-pillar and Square-pillar micro-structured surfaces show the higher CA when the parameters were the same since the obtuse angle may avoid the stress concentration on the solid-liquid contact line. The CAs was first increased and then decrease on all three shapes. The micropillar structured surfaces with the space between the pillars $b=10 \mu \mathrm{m}$ decreased when the temperatures 


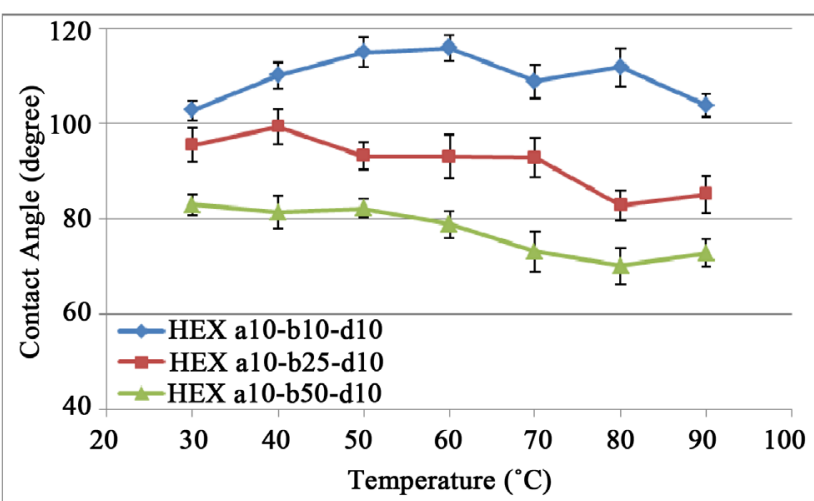

(a)

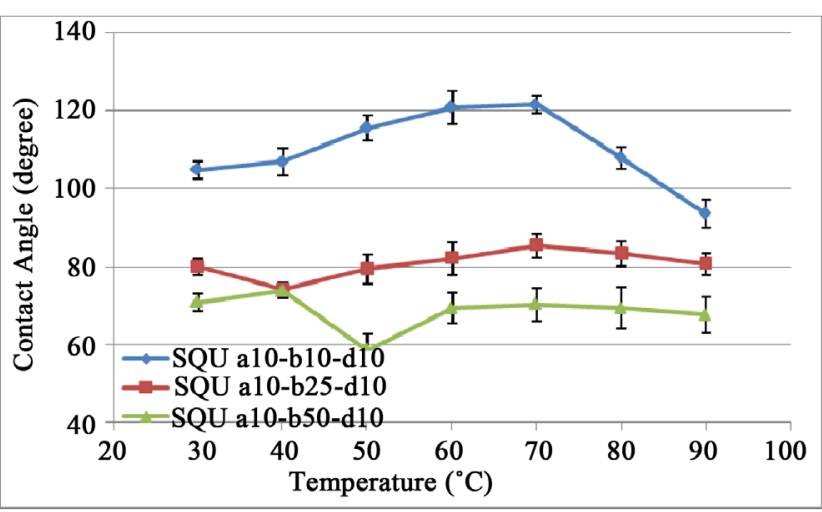

(c)

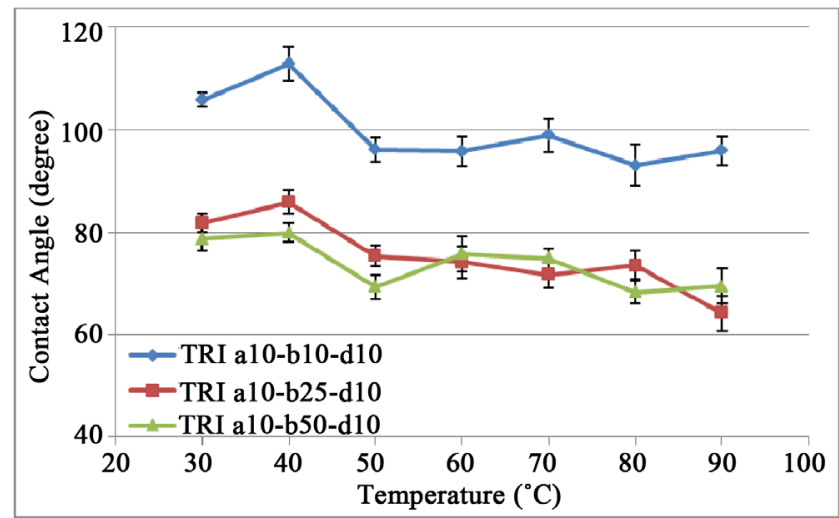

(e)

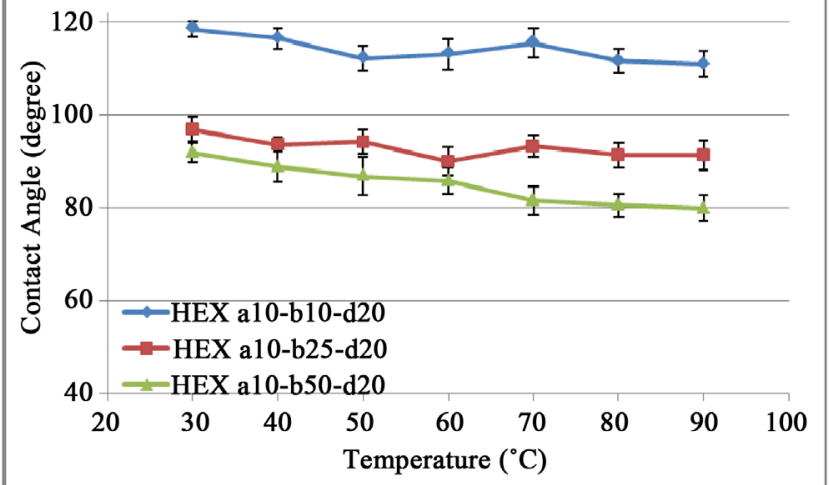

(b)

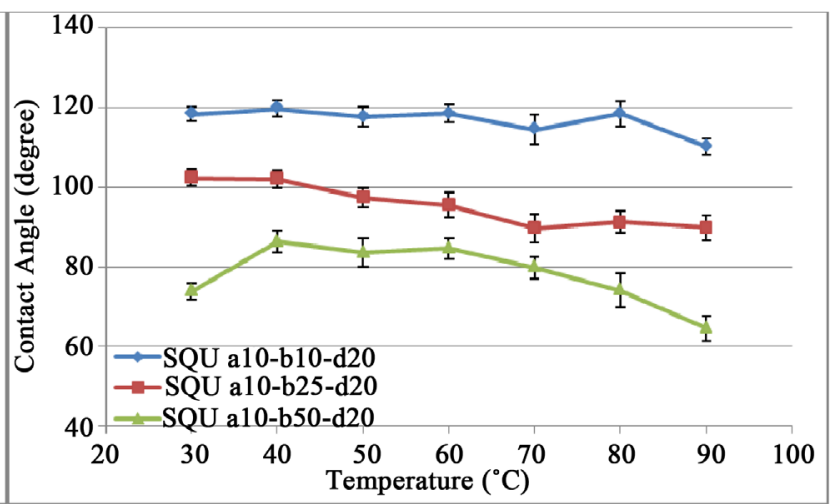

(d)

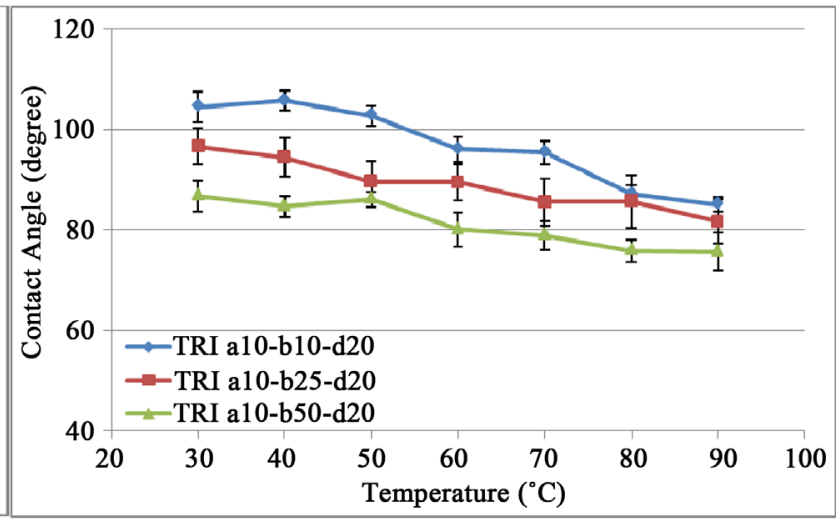

(f)

Figure 6. Contact angle curve of the same shape's micro-structured surface at different temperatures. (a) and (b) show the contact angles at different temperatures on the hexagon micro-pillar surfaces with $d=10 \mu \mathrm{m}$ and $20 \mu \mathrm{m}$ respectively; (c) and (d) shows the contact angles at different temperatures on the square micro-pillar surfaces with $d=10 \mu \mathrm{m}$ and $20 \mu \mathrm{m}$ respectively; (e) and (f) shows the contact angles at different temperatures on the triangle micro-pillar surfaces with $d=10 \mu \mathrm{m}$ and $20 \mu \mathrm{m}$, respectively.

became high. This phenomenon reduces rapidly when the space between the pillars increases, but this was nearly invisible in the CA measurements on the micro-structured surface with apillar depth of $d=20 \mu \mathrm{m}$. The CA on triangle-pillar surface with the space between the pillars $b=10 \mu \mathrm{m}$ and pillar depth of $d=10 \mu \mathrm{m}$ went down when the temperature rose over $40^{\circ} \mathrm{C}$, but for Square- and Hexagon-pillar surface, the $\mathrm{CA}$ went down from $70^{\circ} \mathrm{C}$ and $60^{\circ} \mathrm{C}$ respectively 


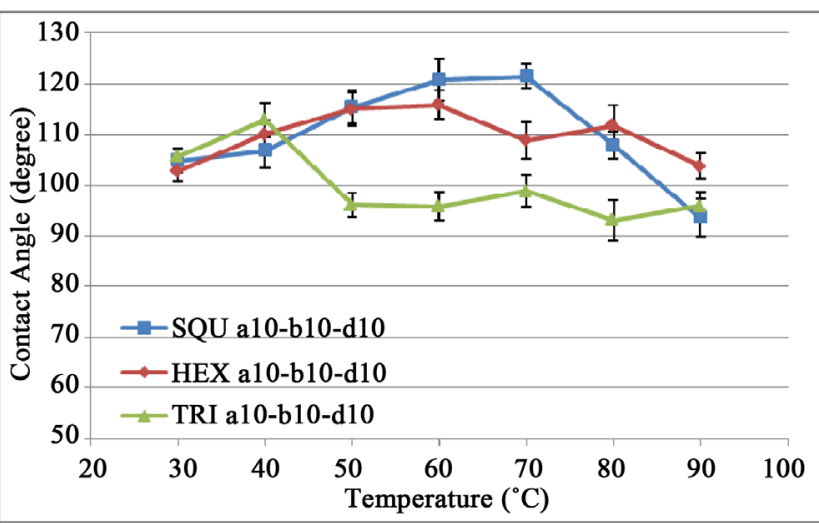

(a)

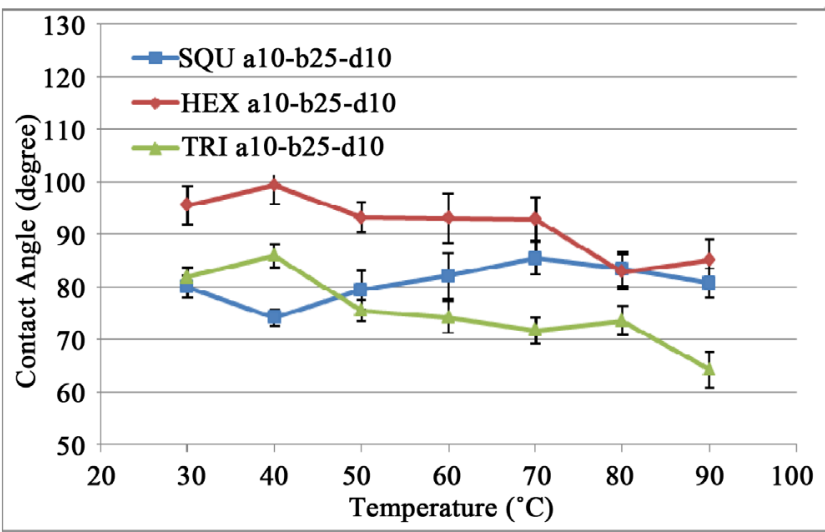

(c)

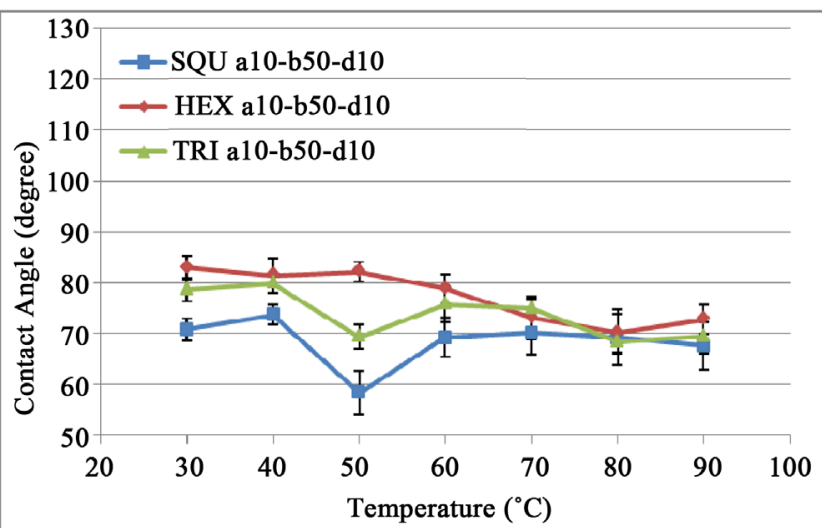

(e)

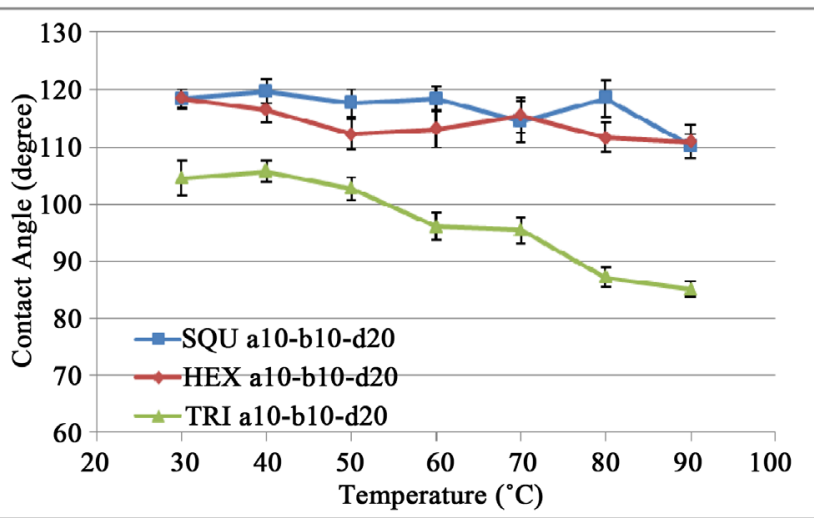

(b)

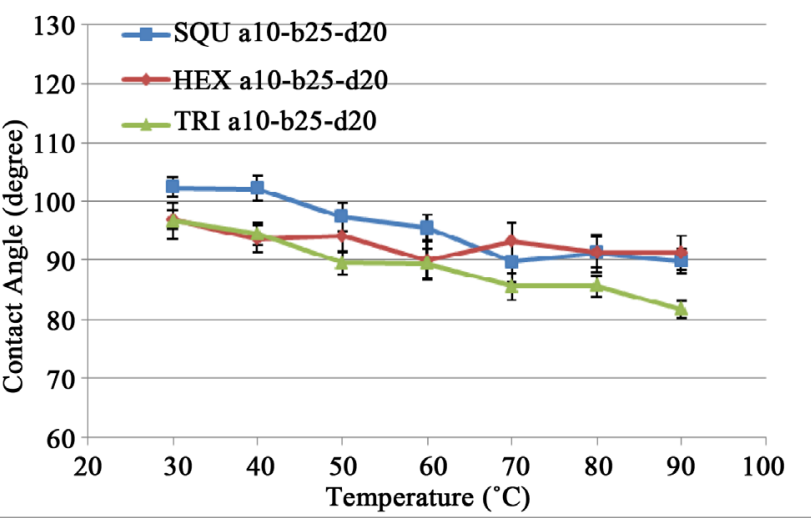

(d)

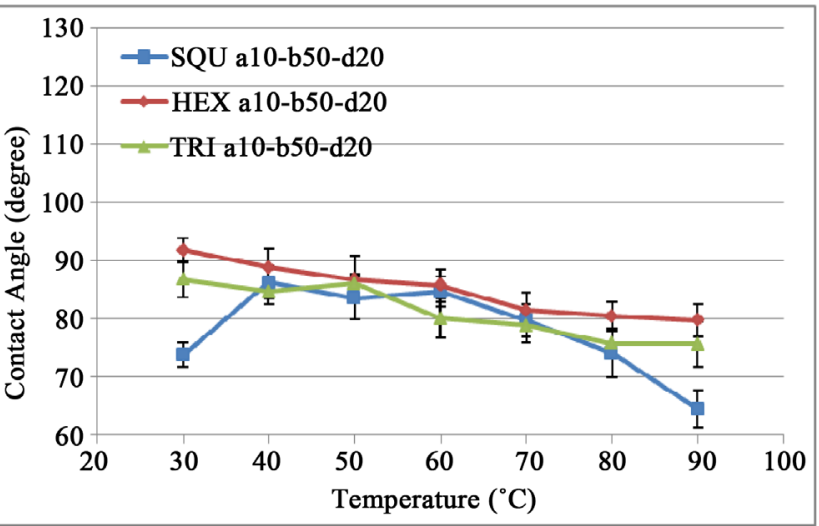

(f)

Figure 7. Contact angle curve of the same designed parameter's micro-structured surface at different temperatures. (a), (c), and (e) show the contact angles at different temperatures on the three shapes with micro-pillar surfaces with space $b=10 \mu \mathrm{m}, 25 \mu \mathrm{m}$, and $50 \mu \mathrm{m}$ respectively when the depth $d=10 \mu \mathrm{m}$; (b), (d), and (f) show the contact angles at different temperatures on the three shapes with micro-pillar surfaces and space $b=10 \mu \mathrm{m}, 25 \mu \mathrm{m}$ and $50 \mu \mathrm{m}$ respectively when the depth $d=20 \mu \mathrm{m}$.

(Figure 7(a)). As shown in Figure 7(c) and Figure 7(e), the Hexagon-pillar surface has higher CA than other two type micro-structured surface with pace between the pillars $b=25 \mu \mathrm{m}$ and $50 \mu \mathrm{m}$ when pillar depth was $10 \mu \mathrm{m}$. However, when pillar depth was $20 \mu \mathrm{m}$, the CA on Square-pillar surface with pace between the pillars $b=10 \mu \mathrm{m}$ and $25 \mu \mathrm{m}$ was higher (see Figure 7(b), Figure 7(d)). 


\section{Conclusions}

The investigation of the wetting behavior of surfaces with different micro-structures from $30^{\circ} \mathrm{C}$ to $90^{\circ} \mathrm{C}$ was described in this paper. Nine kinds of micro-structured surfaces with different wettability were successfully fabricated using the photolithography and ICP etching techniques. The wetting behavior of a $10 \mu \mathrm{L}$ DI water droplet was observed on the fabricated surfaces.

According to the observed results, all the droplets were Cassie-Baxter state on the micro-structured surfaces except the droplet on the sample SQU a10-b50-d10 at $50^{\circ} \mathrm{C}$. A wider pillar-structure space causes the contact angle to decrease. The contact angles increase when the pillar heights increase. When the pillar height was $10 \mu \mathrm{m}$, the CAs was first increased and then decreased with temperature rising. However, the result shows that relationship of temperature and CAs on the micro-structured surfaces with pillar height $d=20 \mu \mathrm{m}$ was nearly linearly dependent. The contact angles were fluctuated by both the temperature change and the microstructure effect on the three-phase contact line.

\section{Acknowledgements}

The authors would like to gratefully acknowledge support by the National Natural Science Foundation of China (Grant No. 51405383).

\section{Conflicts of Interest}

The authors declare no conflicts of interest regarding the publication of this paper.

\section{References}

[1] Marik, T. (2011) Study and Applications of Liquid Behavior on Microtextured Solid Surfaces. PhD Thesis, University of Illinois at Urbana Champaign.

[2] Tadmor, R., Das, R., Gulec, S., Liu, J., N'guessan, H.E., Shah, M., Wasnik, P.S. and Yadav, S.B. (2017) Solid-Liquid Work of Adhesion. Langmuir, 33, 3594-3600. https://doi.org/10.1021/acs.langmuir.6b04437

[3] Feng, L., Li, S., Li, Y., Li, H., Zhang, L., Zhai, J., Song, Y., Liu, B., Jiang, L. and Zhu, D. (2002) Super-Hydrophobic Surfaces: From Natural to Artificial. Advanced Materials, 14, 1857-1860. https://doi.org/10.1002/adma.200290020

[4] Liu, M.J., Wang, S.T., Wei, Z.X., Song, Y.L. and Jiang, L. (2009) Bioinspired Design of a Superoleophobic and Low Adhesive Water/Solid Interface. Advanced Materials, 21, 665-669. https://doi.org/10.1002/adma.200801782

[5] Gao, X.F. and Jiang, L. (2004) Biophysics: Water-Repellent Legs of Water Striders. Nature, 432, 36, https://doi.org/10.1038/432036a

[6] Zheng, Y., Gao, X. and Jiang, L. (2007) Directional Adhesion of Superhydrophobic Butterfly Wings. Soft Matter, 3, 178-182. https://doi.org/10.1039/B612667G

[7] Gao, X., Yan, X., Yao, X., Xu, L., Zhang, K., Zhang, J., Yang, B. and Jiang, L. (2007) The Dry-Style Antifogging Properties of Mosquito Compound Eyes and Artificial Analogues Prepared by Soft Lithography. Advanced Materials, 19, 2213-2217. https://doi.org/10.1002/adma.200601946

[8] Parker, R. and Lawrence, C.R. (2001) Water Capture by a Desert Beetle. Nature, 
414, 33. https://doi.org/10.1038/35102108

[9] Zheng, Y.M., Bai, H., Huang, Z.B., Tian, X.L., Nie, F.-Q., Zhao, Y., Zhai, J. and Jiang, L. (2010) Directional Water Collection on Wetted Spider Silk. Nature, 463, 640-643. https://doi.org/10.1038/nature08729

[10] Wenzel, R.N. (1936) Resistance of Solid Surfaces to Wetting by Water. Industrial \& Engineering Chemistry, 28, 988-994. https://doi.org/10.1021/ie50320a024

[11] Wang, J.Y., Do-Quang, M., Cannon, J.J., Yue, F., Suzuki, Y., Amberg, G. and Shiomi, J. (2015) Surface Structure Determines Dynamic Wetting. Scientific Reports, 5, 8474. https://doi.org/10.1038/srep08474

[12] Zong, D., Yang, Z. and Duan, Y. (2018) Dynamic Spreading of Droplets on Lyophilic Micropillar-Arrayed Surfaces. Langmuir, 34, 4417-4425. https://doi.org/10.1021/acs.langmuir.7b04358

[13] Qiao, S., Li, S., Li, Q., Li, B., Liu, K. and Feng, X. (2017) Friction of Droplets Sliding on Microstructuredsuperhydrophobic Surfaces. Langmuir, 33, 13480-13489. https://doi.org/10.1021/acs.langmuir.7b03087

[14] Fang, W., Guo, H., Li, B., Li, Q. and Feng, X. (2018) Revisiting the Critical Condition for the Cassie-Wenzel Transition on Micropillar-Structured Surfaces. Langmuir, 34, 3838-3844. https://doi.org/10.1021/acs.langmuir.8b00121

[15] Yamamoto, K. and Ogata, S. (2008) 3-D Thermodynamic Analysis of Superhydrophobic Surfaces. Journal of Colloid and Interface Science, 326, 471-477. https://doi.org/10.1016/j.jcis.2008.06.044

[16] Zhang, T., Wang, J., Chen, L., Zhai, J., Song, Y. and Jiang, L. (2011) High Temperature Wetting Transition on Micro- and Nanostructured Surfaces. Angewandte Chemie, 123, 5311-5314. https://doi.org/10.1002/anie.201007262

[17] Hashim, J., Looney, L. and Hashmi, M.S.J. (2001) The Wettability of SiC Particles by Molten Aluminium Alloy. Journal of Materials Processing Technology, 119, 324-328. https://doi.org/10.1016/S0924-0136(01)00975-X

[18] Liu, Y., Chen, X. and Xin, J. (2009) Can Superhydrophobic Surfaces Repel Hot Water? Journal of Materials Chemistry, 19, 5602-5611. https://doi.org/10.1039/b822168e

[19] Kim, B.S., Lee, H., Shin, S., Choi, G. and Cho, H.H. (2014) Interfacial Wicking Dynamics and Its Impact on Critical Heat Flux of Boiling Heat Transfer. Applied Physics Letters, 105, Article ID: 191601. https://doi.org/10.1063/1.4901569

[20] Wang, N., Zhao, Y. and Jiang, L. (2008) Low-Cost, Thermoresponsive Wettability of Surfaces: Poly(N-isopropylacrylamide)/Polystyrene Composite Films Prepared by Electrospinning. Macromolecular Rapid Communications, 29, 485-489. https://doi.org/10.1002/marc.200700785

[21] Sun, T., Liu, H., Song, W., Wang, X., Jiang, L., Li, L. and Zhu, D. (2004) Responsive Aligned Carbon Nanotubes. Angewandte Chemie, 116, 4663-4666. https://doi.org/10.1002/anie.200460774

[22] Liu, Y., Komatsuzaki, H., Duan, Z., Imai, S. and Nishioka, Y. (2011) Diffuser Micropump Structured with Extremely Flexible Diaphragm of 2- $\mu$ m-thick Polyimide Film. Japanese Journal of Applied Physics, 50, 453-455. https://doi.org/10.1143/JJAP.50.04DK15

[23] Komatsuzaki, H., Suzuki, K., Liu, Y., Kosugi, T., Ikoma, R. and Nishioka, Y. (2011) Flexible Polyimide Micropump Fabricated Using Hot Embossing. Japanese Journal of Applied Physics, 50, 06GM09. https://doi.org/10.1143/JJAP.50.06GM09

[24] Tsai, P.C., Lammertink, R.G.H., Wessling, M. and Lohse, D. (2010) Evapora- 
tion-Triggered Wetting Transition for Water Droplets upon Hydrophobic Microstructures. Physical Review Letters, 104, Article ID: 116102. https://doi.org/10.1103/PhysRevLett.104.116102

[25] Daniel, S., Chaudhury, M.K. and Chen, J.C. (2001) Fast Drop Movements Resulting from the Phase Change on a Gradient Surface. Science, 291, 633-636. https://doi.org/10.1126/science.291.5504.633

[26] Linke, H., Alemán, B.J., Melling, L.D., Taormina, M.J., Francis, M.J., Dow-Hygelund, C.C., Narayanan, V., Taylor, R.P. and Stout, A. (2006) Self-Propelled Leidenfrost Droplets. Physical Review Letters, 96, Article ID: 154502. https://doi.org/10.1103/PhysRevLett.96.154502

[27] Young, T. (1805) An Essay on the Cohesion of Fluids. Philosophical Transactions of the Royal Society of London, 95, 65-87. https://doi.org/10.1098/rstl.1805.0005

[28] Cassie, A.B.D. and Baxter, S. (1944) Wettability of Porous Surfaces. Faraday Society, 40, 546-551. https://doi.org/10.1039/tf9444000546

[29] Lv, C., Yang, C., Hao, P., He, F. and Zheng, Q. (2010) Sliding of Water Droplets on Microstructured Hydrophobic Surfaces. Langmuir, 26, 8704-8708. https://doi.org/10.1021/la9044495

[30] Zheng, Q., Lv, C., Hao, P. and Sheridan, J. (2010) Small Is Beautiful, and Dry. Science China Physics Mechanics \& Astronomy, 53, 2245-2259. https://doi.org/10.1007/s11433-010-4172-1

[31] Wong, T.-S. and Ho, C.-M. (2009) Dependence of Macroscopic Wetting on Nanoscopic Surface Textures. Langmuir, 25, 12851-12854. https://doi.org/10.1021/la902430w

[32] Lv, C., Wang, Z., Wang, P. and Tang, X. (2012) Photodegradable Polyurethane Self-Assembled Nanoparticles for Photocontrollable Release. Langmuir, 28, 9387-9394. https://doi.org/10.1021/la301534h

[33] Susarrey-Arce, A., Marín, Á.G., Nair, H., Lefferts, L., Gardeniers, J.G.E., Lohse, D. and van Houselt, A. (2012) Absence of an Evaporation-Driven Wetting Transition on Omniphobic Surfaces. Soft Matter, 8, 9765-9770. https://doi.org/10.1039/c2sm25746g

[34] Tadmor, R. (2004) Line Energy and the Relation between Advancing, Receding, and Young Contact Angles. Angmuir, 20, 7659-7664. https://doi.org/10.1021/la049410h 